

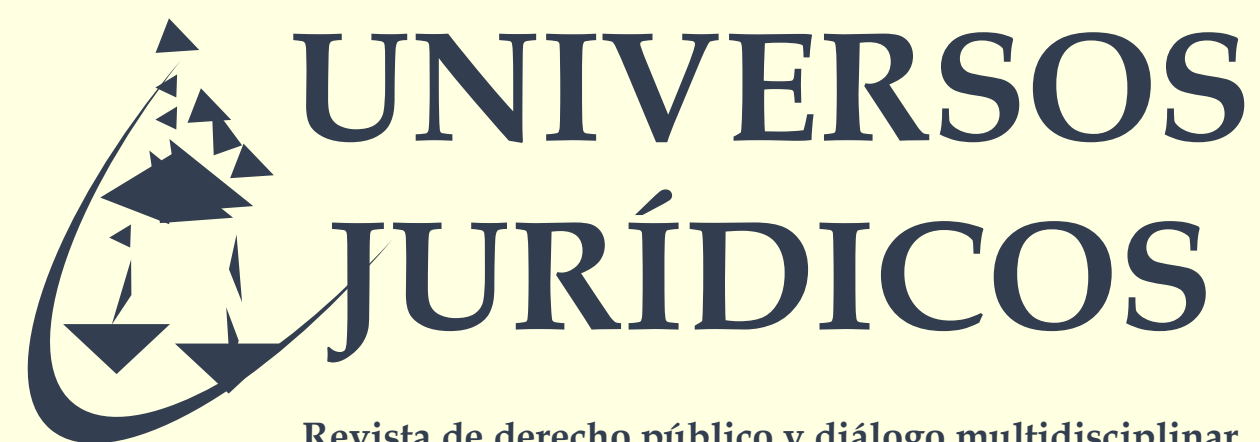

Revista de derecho público y diálogo multidisciplinar

\section{PÁGINA LEGAL}

Universos Jurídicos, año 8, No. 14, mayo-octubre 2020, es una publicación semestral editada por la Universidad Veracruzana a través del Instituto de Investigaciones Jurídicas. Lomas del estadio S/N, col. Centro. C.P. 91000. Xalapa, Veracruz, México. Teléfono +52 (228)8186841. http:// www.uv.mx/iij, fabaez@uv.mx. Reserva de Derechos al uso exclusivo No. 04-2013041509530000-203, ISSN 2007-9125, Ambos otorgados por el Instituto Nacional del Derecho de Autor. Responsable de la última actualización de este número: Instituto de Investigaciones Jurídicas, calle Hermenegildo Galeana esquina 7 de noviembre S/N, Zona Centro, C.P. 91000 . Fecha de la última modificación de este número: 30 de mayo de 2020.

Las opiniones expresadas por los autores no necesariamente reflejan la postura del editor de la publicación. 


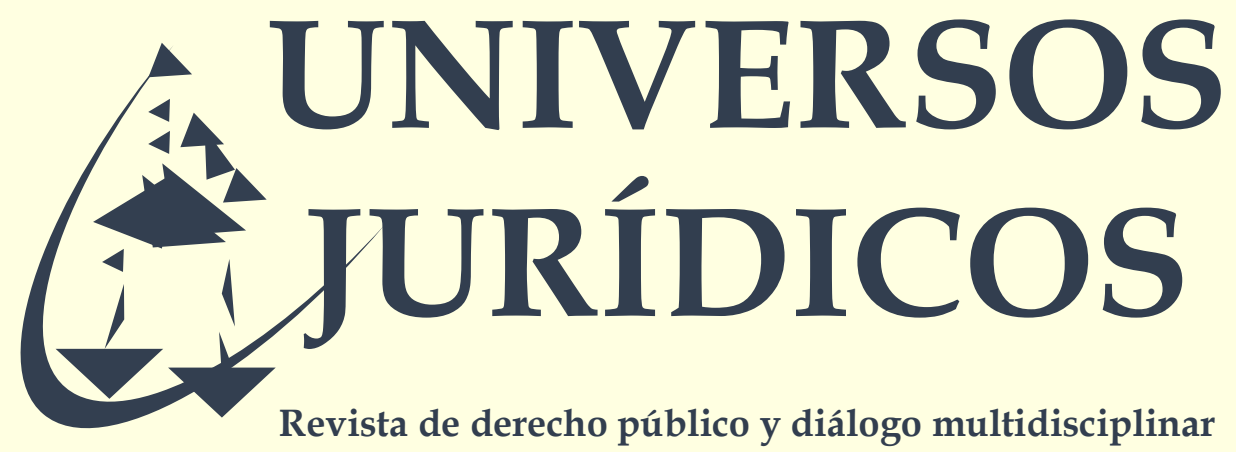

Directora del Instituto de Investigaciones Jurídicas

Petra Armenta Ramírez

\section{Consejo Editorial}

Andre Braen (Université d'Ottawa, Canadá)

Ariadna Estévez López (Universidad Nacional Autónoma de México, México)

Carlos Báez Silva (Escuela Libre de Derecho, México)

David Cienfuegos Salgado (Universidad Nacional Autónoma de México, México)

Gloria del Castillo Alemán (Facultad Latinoamericana de Ciencias Sociales, México)

Jaqueline del Carmen Jongitud Zamora (Universidad Veracruzana, México) José Francisco Báez Corona (Universidad Veracruzana, México)

Luis Daniel Vázquez Valencia (Facultad Latinoamericana de Ciencias Sociales, México)

Luis Ignacio Gordillo Pérez (Universidad de Deusto, España)

Miguel Carbonell (Universidad Nacional Autónoma de México, México)

Miriam de los Ángeles Díaz Córdoba (Universidad Veracruzana, México)

Orisell Richards Martínez (Universidad de la Habana, Cuba)

Petra Armenta Ramírez (Universidad Veracruzana, México)

Yesenia del Carmen Trejo Cruz (Universidad Veracruzana, México)

\section{Diseño y formación editorial}

María del Rocío Viveros Hernández (Universidad Veracruzana, México)

Karina Nohemí Martínez Meza (Universidad Veracruzana, México)

\section{Imagen de portada}

Recuperada de internet, utilizada al amparo del artículo 148 de la Ley Federal de Derechos de Autor en México, el cual permite la reproducción de fotografías e ilustraciones difundidos por cualquier medio, si esto no hubiese sido expresamente prohibido por el titular del derecho o el autor no aparece identificado en la misma. 


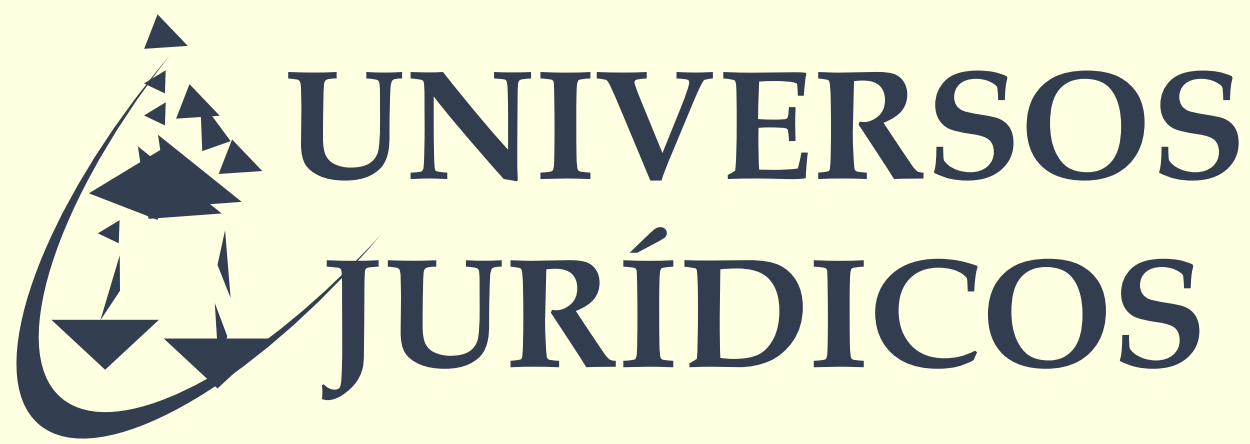

Revista de derecho público y diálogo multidisciplinar

\section{CONTENIDO}

LA PREVENCIÓN DEL DELITO A LA LUZ DEL PARADIGMA $1-35$ RESTAURATIVO EN MÉXICO: UN ESTUDIO SOBRE EL DISEÑO DE POLÍTICA CRIMINAL PERIODO 2013-2019.

(CRIME PREVENTION IN LIGHT OF THE RESTORATIVE PARADIGM IN MEXICO: A STUDY ON THE DESIGN OF CRIMINAL POLICY PERIOD 2013-2019.)

Alan Jair García Flores, Leticia Espinosa Nicolás

EDUCACIÓN VIRTUAL Y SU MARCO REGULATORIO EN MÉXICO ANTE LA EMERGENCIA SANITARIA POR COVID-19

$36-60$

(VIRTUAL EDUCATION AND ITS REGULATORY FRAMEWORK IN MEXICO IN THE FACE OF THE HEALTH EMERGENCY DUE TO COVID-19)

José Francisco Báez Corona, Octavio Ruíz Méndez

SÍNDROME DE BURNOUT LABORAL (SB) O DESGASTE $61-84$ PROFESIONAL BAJO LA PERSPECTIVA DEL DERECHO DEL TRABAJO

(BURNOUT SYNDROME UNDER THE PERSPECTIVE OF LABOR LAW) Aleida Elvira Martínez Harlow 


\section{EL PARADIGMA DE DERECHOS HUMANOS Y LA INUTILIDAD}

85-105 DEL ESTADO DE INTERDICCIÓN EN EL DERECHO FAMILIAR MEXICANO

(THE HUMAN RIGHTS PARADIGM AND THE USELESSNESS OF THE

STATE OF INTERDICTION IN MEXICAN FAMILY LAW)

Rodrigo Tovar Cabañas, Ubaldo Márquez Roa

EL PAPEL DEL CONGRESO DE AGUASCALIENTES FRENTE A LA

116-119 CORRUPCIÓN

(THE ROLE OF THE AGUASCALIENTES CONGRESS AGAINST

CORRUPTION)

Julio César García Landero 